\title{
Hypnosis and Medicine: An Historical Examination
}

\author{
Niamh Flynn* \\ The Galway Clinic, National University of Ireland, Ireland \\ Received date: February 08, 2019; Published date: March 01, 2019 \\ *Corresponding author: Niamh Flynn, The Galway Clinic, Doughiska, Galway, Republic of Ireland \& formerly of National University of Ireland, \\ Galway, Ireland
}

Abstract

This article explores the history of the ancient art of hypnosis down through the years. It examines the efficacy of hypnosis as a treatment for chronic pain and outlines theories and models of hypnosis. The biological correlates of hypnosis are delineated and the application of hypnotherapy and its place in modern medicine in the treatment of chronic pain is also discussed.

Keywords: Hypnosis; Hypnotherapy; Complementary and Alternative Medicine; Chronic Pain and Hypnosis

Abbreviations: HH: Higher Hypnotizability; SHSSC: Stanford Hypnotic Susceptibility Scales; FMD: Flow-Mediated Vasodilation; HGSHS: A Harvard Group Scale of Hypnotic Susceptibility; HIP: Hypnotic Induction Profile; CAHS: A Computer Assisted Hypnosis Scale; TAS: Tellegan Absorption Scale; MRI: Magnetic Resonance Imaging; PET: Positron Emission Tomography

\section{Introduction}

Hypnosis is a heightened state of awareness typified by specific objective indicators such as eyes fluttering and subjective indicators such as time distortion. The state of hypnosis typically involves an induction followed by suggestions. The ability of someone to experience a hypnotic state and the extent to which they can be hypnotized is described as hypnotizability or hypnotic susceptibility. Complementary and alternative medicine (CAM) represents a group of diverse medical and healthcare therapies, systems and products which are not part of conventional medicine [1]. In a review of the efficacy of specific CAM as interventions for chronic pain, Tan et al. [1] found that some CAM were effective, and others required additional research. Hypnosis was reviewed under the mind-body medicine cateogry. Studies examined in the review concluded that hypnosis was an efficacious treatment for chronic pain. In addition, the researchers suggested that hypnosis and hypnotic analgesia had been underutilised as treatments for clinical conditions. Other research supports this review and examines the use of hypnosis being underutilised as a treatment for clinical conditions

Berman \& Swyers [2], for example, looked at studies which used a variety of complementary treatments for fibromyalgia syndrome. These treatments were divided into three categories: mind-body interventions, acupuncture and manipulative techniques. They found that the strongest support was for the mind-body interventions which included hypnosis. A later review by Elkins, Jensen \& Patterson [3] examined thirteen studies which used hypnosis as a treatment for chronic pain conditions such as cancer, low back pain, arthritis and sickle-cell disease. This review found support to indicate that hypnosis produced significant decreases in pain. The authors pointed out the shortcomings of past studies on chronic pain and hypnosis, most notably the lack of credible controls for placebo or expectation.

Jensen \& Patterson [4], in a separate review of the literature, found a significant body of studies demonstrating the superior nature of hypnosis to medication management, physical therapy and education for the treatment of found a significant body of studies demonstrating the superior nature of hypnosis to medication management, physical therapy and education for the treatment of chronic pain and stated that it could be argued that each of the alternative treatments presumably also enlisted patient expectancy. Hypnotic analgesia consistently results in greater decreases in a variety of pain outcomes when compared with standard care and/or no treatment. A review of randomized controlled trials of hypnotic analgesia for the treatment of chronic and acute pain in adults found hypnosis to be more effective for neuropathic pain or vascular pain than in musculoskeletal pain [5].

\section{Theories and Models of Hypnosis}

While the uses of hypnosis are ubiquitous, and hypnosis can arguably be traced back to the sleep temples utilised by the Greeks and Egyptians over 4000 years ago, academic research in the area of hypnosis as an intervention for chronic pain is relatively recent. Higher hypnotizability $(\mathrm{HH})$ has been associated with relatively greater response to hypnotic analgesic suggestions [6]. Hypnosis has a long history of reducing emotional distress and pain [7]. Psychological factors are accepted as playing a role in the treatment of migraine, for example, with emotional distress 


\section{Current Trends in Clinical \& Medical Imaging}

being cited as the single, most frequent trigger [8]. Bushnell, Čeko \& Low [9], commented on how emotions can affect behaviour, and stated that what makes pain "pain" is "usually the affective component of the experience - that is, how unpleasant it is. It is the unpleasantness that motivates the individual to engage in a behaviour, whether it is to flee, fight or freeze. (p.503)'.

\section{History of Hypnosis}

The earliest reference to hypnosis relates to sleep temples in Egypt (3000-1000 BC) and Greece (2000-500BC) which provided refuge for patients whose healing experience involved hypnotic chanting. Sometime later, Paracelsus, a German-Swiss physician, botanist, alchemist and astrologer who lived from 1493 to 1541 was documented as using hypnotic techniques. He preferred unorthodox methods of healing and is quoted as saying that 'Medicine is not only a science; it is also an art. It does not consist of compounding pills and plasters; it deals with the very processes of life, which must be understood before they may be guided. (www.egs.edu/library/paracelsus/ biography).' He believed that the body could heal itself and that the mind and body are intertwined in the healing process. He is also attributed with being the first person to mention the word 'unconscious', a word used synonymously with 'subconscious' in hypnotic literature and teachings. Two centuries later, Father Maximilian Hell (1720-1792) an Austrian-Hungarian Jesuit developed an interest in magnetism. Among other applications, he used magnets to reduce pain and successfully alleviated his own rheumatic pain using magnets. This attracted the attention of Franz Mesmer who developed his own theories about cosmic fluids in the body. With their unconventional approaches to healing, both men were attributed with introducing the concept of hypnosis to medicine [10].

Terms used in hypnosis such as 'somnambulism', and 'suggestibility' can be traced as far back as the $18^{\text {th }}$ and $19^{\text {th }}$ Centuries to Marquis de Puysegur (1751-1825) and Bernheim (1837-1919) respectively. James Esdaile, a Scottish surgeon (1808-1859) was widely regarded as being one of the most influential people in the world of medicine and hypnosis. Esdaile travelled to Calcutta from England and performed many major operations using hypnoses as the sole anaesthetic, at a time when pain relief was not available [11]. Amongst the operations documented is one which involved the removal of a scrotal tumour weighing 103lbs, (Report of the committee., 1846:26 as quoted in Ernst, 2004).

Hypnosis was subsequently influenced by many well-known figures in psychology such as Freud who studied hypnosis and later replaced it with psycho-analysis, believing that patients could become 'addicted to hypnosis'. Freud also believed that hypnosis did not provide an insight into the processes which led to the formation of the problem [12]. However, as BachnerMelman \& Lichtenberg [12] pointed out, Freud is often criticised for his inexperience in hypnosis. Milton Erickson (1901-1980) could therefore be regarded as the antithesis to Freud as he dedicated 50 years of his life to the study and practice of hypnosis. The term 'Ericksonian hypnosis' is used to describe an approach which tailor's treatment to each patient and in which 'insight is not necessary for change' (p155). As Feldman [13] explained, Erickson rejected psycho-analysis and was, at the time, probably viewed as an anarchist because he broke many of the established rules for the conduct of treatment.

\section{Theories of Hypnosis}

Hypnotizability is considered a stable trait. In a study by Piccione, Hilgard \& Zimbardo [14] hypnotic susceptibility over a 25 -year period had a .75 test-re-test correlation. There are several theories about the concepts underlying hypnotizability (suggestibility). The most prominent theories are dissociation and absorption. More recently these have been divided into 'state theories' and 'non-state theories. State theorists refer to the stability of hypnotizability and the notion that altered states of consciousness explain the trance state. The Neo-dissociation theory and Dissociated Control theory fall into this category.

The neo-dissociation theory posits that higher cognitive functions disengage from what is happening during hypnosis. Ernest Hilgard (1904-2001) who proposed this theory believed that there was also a 'hidden observer' in the mind which was aware of what was being said [15]. In terms of pain, Hilgard believed that while the patient may not experience pain, they were aware and could, at some level, report details about that pain. The dissociated control theory proposed by Woody \& Bowers [16] formerly suggested that there was a segregation of higher-level brain systems in the highly hypnotizable $(\mathrm{HH})$ person during hypnosis which left a dependency on lower level, automatic processes that were influenced by external cues.

Typically, the highly hypnotizable individual will be characterised by his ability to 'get so absorbed in an activity that he tends to lose awareness of where he is' (p.139) [17]. More recent reflections [18] on studies investigating this theory have suggested that the hypnotic state is more complex. Nonstate theories propose that dynamic factors such as motivation, attitudes and expectancy are responsible for hypnotic phenomena. The sociocognitive theorists, who support this view of hypnosis, believe that suggestion will have the same effect as hypnosis on behavioural change. These theorists reject the idea that an altered state of consciousness is necessary for hypnotic experiences [19] and Dienes et al. [20] noted that 'correlates of hypnotic suggestibility are notoriously difficult to find' (p.837.) The researchers looked at dissociation and cognitive inhibition, the two proposed correlates of hypnotizability on which two of the better-known theories of hypnotic suggestibility - Neo Dissociation and Dissociated Control Theory - are founded. Their results, from a study population of 180 individuals, showed no correlation between hypnotic suggestibility and dissociation or cognitive inhibition.

The advent of imaging techniques has allowed us to see physiological differences in the brains of those classified as 'highs' 
or 'HH's' and 'lows' or 'LH's'. For example, Horton, Crawford, Harrington \&Downes [21] used MRI with HHs and LHs and found that HHs had a significantly $(\mathrm{P}<0.0003)$ larger $(31.8 \%)$ rostrum, the part of the corpus callosum involved in the transfer of information between prefrontal cortices and involved in the allocation of attention, than the LHs. Higher Hypnotisability $\mathrm{(HH})$ has been associated with relatively greater response to hypnotic analgesic suggestions [22] and HH's experience the most significant relief [23]. Coupled with the growing interest in physiological correlates of hypnosis, non-state theories of hypnosis are now being challenged.

\section{The Construct of Hypnotizability}

Green, Barabasz, Barrett \& Montgomery [24] described hypnotizability as a cognitive, multidimensional trait related to the ability to accept hypnotic suggestions and stated that it can be measured by hypnotizability scales. A number of scales are employed in research settings to assess hypnotizability such as The Hypnotic Induction Profile (HIP) [25] or Stanford Hypnotic Susceptibility Scales (SHSS:C) [26] and a computergenerated system has been developed to test hypnotic ability [27]. While being highly hypnotizable ( $\mathrm{HH}$ ) is associated with excellent memory, a capacity for intense concentration and an easy acceptance of logical incongruities and those who fall in to this category can affiliate with new events and respond rapidly to treatment [28], being highly hypnotizable is not necessary for successful analgesia using hypnosis [23]. The effects can also persist over time. Some studies have found no relationship between hypnotizabiltiy and performance, although these are in the minority. In a study examining the relationship between information processing and hypnosis, Friedman, Taub, Sturr \& Monty [29] looked at visual processing speed in hypnotized and in non-hypnotized subjects. Hypnotized subjects were found to be significantly faster than non-hypnotized subjects in the speed of information processing during a backward masking task.

The Harvard Group Scale of Hypnotic Susceptibility (HGSHS: A) [30] is the most widely used in hypnosis research because of its cost effectiveness and the ability to test several people at the same time [30]. However, as Angelini et al. [30] pointed out, both group testing and individual testing of hypnotic responsiveness have their limitations. They highlighted the fact that social interaction in a group may skew findings by increasing or decreasing the desire to perform in front of others. Individual testing on the other hand may be influenced by the individual's desire to 'please' the researcher. The Stanford Scale of Hypnotic Susceptibility for C [31] is also used frequently in studies. It consists of twelve items and one mark is given to each item. It is time consuming, however; a shorter version of this scale has been developed [32].

The Tellegan Absorption Scale (TAS) measures how absorbed a person becomes in an activity or an object. It only measures one proposed correlate of hypnotizability (absorption) although it has been used as a predictor of hypnotic suggestibility [33]. A computer assisted hypnosis scale (CAHS) was devised by Grant \& Nash [34] as a means of assessing hypnotizability online. The scale was shown to be psychometrically sound [34] for measuring hypnotic ability and it compared favourably with the SHSS:C on three dimensions, namely behavioural, subjective depth and relational involvement. However, the software has not progressed from a DOS Windows programme and so is no longer in use and no longer available for research purposes (M.R. Nash personal communication 12th September 2011).

The eye roll test for hypnotizability was devised by Herbert Spiegel in 1972 following an observation that participants who were highly hypnotizable had the unusual capacity to roll their eyes upwards so that mainly just the white part of the eye is visible. In $75 \%$ of 2,000 consecutive clinical cases, a five second assessment using the Eye Roll sign accurately predicted the level of hypnotizability [35]. In one out of four cases, positive eye roll was misleading. Spiegel later elaborated on the eye roll test, developing the Hypnotic Induction Profile (HIP) which takes approximately ten minutes to perform. As Spiegel [25] pointed out, laboratory tests for hypnotizability can take 60 minutes or more per person, they can fatigue the client, some of the instructions are aesthetically inappropriate and potentially embarrassing.

The high correlation between the eye roll test and hypnotizability prompted Spiegel to speculatethathypnotizability is physiologically determined and he suggested that this trait is either genetically pre-determined or is a skill learned early in life [35]. One study by Orne et al. [36] found that the HIP did not correlate highly with other scales, which may explain why HIP assessment does not appear all that frequently as a test of hypnotizability in the literature. It must be noted, however, that the HIP was tested on 2,000 psychotherapy cases [35] as opposed to laboratory tests which have been standardized on non-patients i.e. college students [25]. The physiological investigations with respect to assessing hypnotisability are relatively recent despite these earlier observations by Spiegel. Stoelb, Molton, Jensen \& Patterson [37] in a review of the literature on hypnotic analgesia for adults, noted that hypnotisability was associated with hypnosis treatment outcomes.

Santarcangelo \& Sebastiani [38] were interested in looking at the changes in autonomic activity in response to stress and in relation to hypnotizability and hypnosis. Their research supported the state-theory of hypnosis; they found that in an awake situation, when asked to recall an unpleasant situation, there was no cardiac response from either group. When the exercise was repeated following a hypnotic induction, individuals who are highly hypnotizable showed autonomic changes. The researchers attributed this to the greater capacity for imagery-attentional capabilities among HHs. They explored the concept further by measuring post-ischaemic flow-mediated vasodilation (FMD) as they were interested in seeing whether this key pathophysiological variable in triggering cardiovascular 


\section{Current Trends in Clinical \& Medical Imaging}

events would be influenced by suggestion. They found that highs have a natural protection against stress and that their natural tendency to engage in multiple spontaneous episodes of relaxation could have led to persistent vascular changes which were favourable to them, in terms of protection against stress at vascular level. It is unclear whether hypnotizability and the benefits experienced by HHs are related to genetics. Interest in genetics and hypnotizability has come to the forefront only in the past fifteen years and is still in its infancy. One study [39] found that participants with the met/val COMT heterozygote geno-type scored highest on hypnotizability as assessed by the Stanford Hypnotic Susceptibility Form C (SHSS:C). Geno-type is the genetic constitution of the person which can determine the potentials limitations of that individual. Lichtenberg et al. [39] pointed out that post-hoc testing revealed a significant difference between the val/met vs val/val genotype. Individuals tested who had the met/val COMT heterozygote gene type showed the highest mean values for hypnotizability.

The researchers suggested that this may be related to dopamine activity. Those with the met allele, they explained, would be expected to have higher dopaminergic tone and low COMT activity would raise dopamine levels; higher dopamine levels would augment attentional processes. But the researchers pointed out that it is likely that other genes are involved in hypnotizability and their findings should be treated with caution. Spiegel and King [40] also reported a correlation between hypnotizability and homovanllic acid (HVA), a dopamine metabolite. More recent support of an association between higher hypnotizability and a genetic association with the COMT gene comes from a study of 127 Hungarian young adults conducted by Skekely et al. [41]. On one level, their findings corroborate the findings of Lichtenburg et al. [39] and Raz [42]. However, Szekely et al. [41] found that hypnotizability scores were highest in the Val/Val homozygote group, scores in the Val/Met hetrozygote group were lower and Met/Met homozygotes demonstrated the lowest hypnotizability. The researchers suggested that the differences may be due to differences in hypnotizability measurement scales used or differences in population structure and ethnicity.

\section{Biological Correlates of Hypnosis}

The placebo effect is now universally recognised in the field of pain [43]. A placebo is an inert substance used for psychological effect, and frequently employed in drug comparison trials. Examining the physiological correlates of placebo, Benedetti \& Amanzio [44] observed that a placebo response has the capacity to increase pain (hyperalgesia) and decrease pain (analgesia) depending on the instructions given to a patient when administering the tablet. If the patient was told that the pill was hyperalgesic, an increase in pain could occur. Conversely, if the instructions were directed towards a decrease in pain, a decrease in pain could occur. Exploring the neurobiology of this phenomenon, the researchers pointed to evidence showing that the opioid antagonist naloxone has the capability to reduce placebo analgesia. Poistron Emission Tomography scans have shown that the exact same pathways are activated in the brain by both placebo and an opiod drug, and furthermore when a substance designed to block a placebo analgesic response, e.g. Naloxone, is administered, it was successful in preventing the pain relief which would otherwise would have ensued as a result of the placebo. This does not occur with hypnosis. That is to say that when hypnotic analgesia (as opposed to placebo analgesia) is utilised, naloxone is not effective in blocking the pain relief which occurs following analgesic suggestions given during hypnosis [45].

It is therefore reasonable to assume that hypnosis works on a very different physiological basis to placebo.Words and suggestions are clearly powerful tools both in the waking state and in the hypnotic state. Nusbaum et al. [46] described a suggestion as 'a colourful communication given to induce a specific, involuntary and often unconscious response by the subject (P.28)'. The extent of the power of words was demonstrated very clearly in an article by Benedetti [43] who described an experiment where post operative oral surgery patients were divided into two groups. One group were openly given an injection of what they perceived to be morphine, which was actually a placebo and the other group were given 6 to $8 \mathrm{mg}$ of morphine by way of a hidden infusion, so they did not know when the painkiller was being injected. Both had the same painrelieving effect, leading the researchers to surmise that telling the patient that they are receiving six to eight miligrams of morphine (when it was actually a placebo) was as powerful as an actual 6 to $8 \mathrm{mg}$ of morphine.

The researchers only noticed an increased analgesic effect when the hidden morphine dose was increased to $12 \mathrm{mg}$. Words and suggestions delivered in an hypnotic state are even more powerful. One research study by Nusbaum et al. [46] examined the way in which analgesic suggestions given to low back pain patients might alter the physiological processes in the brain. They found that during hypnosis, both analgesic suggestions of the direct (e.g. "you can sense a numb feeling spreading in that area") and the indirect variety (e.g. "it may be that now. or perhaps some time later... you start to notice you feel more comfortable.") were equally successful in decreasing pain intensity by $64 \%$. In the group who were not hypnotized, only the direct suggestions were effective and the decrease in pain intensity was $20 \%$. Although direct analgesic suggestions were effective in both normal alertness and hypnotic conditions, the results confirmed increased efficacy of appropriate suggestions on pain modulation in the hypnotic state.

A significant finding of this functional imaging study was that different networks in the brain were activated depending on whether the suggestions were given in the hypnotic state or in normal alertness. For those in the group who were not hypnotized, (normal alertness) the parts of the brain which deal 
with problem solving, attention, and decision making (cognitive network) and the parts of the brain which deal with intensity and location of pain (sensory network) were activated. In the hypnotic state, the same analgesic suggestions activated an emotional weighted network.

The recent advent of imaging techniques such as Magnetic Resonance Imaging (MRI) and Positron Emission Tomography (PET) has permitted a new dimension to research in this area. Horton, Crawford, Harrington \& Downs [47] examined the brains of highly hypnotizable individuals using MRI and found that the rostrum in the anterior corpus callosum was $31 \%$ greater in volume than the rostrum volume of low hypnotizable individuals. Although the sample size of the study was small (8 HH's) a considerable effect size was found, and the results were statistically significant. Horton et al. [47] concluded from this research that this physiological distinction would explain the more effective frontal attentional systems and gating of emotions, cognition and sensation that is attributed to HH's. Other techniques investigating brain activity during hypnosis, for example EEG, have also been examined in the hypnosis literature. Burrows et al. [48] examined the literature comparing electroencephalogram (EEG) activity for low and highly hypnotizable individuals.

They provided evidence of studies which show that as individuals enter hypnosis, irrespective of hypnotizability, EEG theta power increased although, prior to hypnotic induction, in a normal waking state $\mathrm{HHs}$ are more likely to generate more theta than LHs. The authors suggested that 'theta power (3-7 $\mathrm{Hz}$ ) hypothesized to be associated with focused attention [49] is positively related to hypnotic susceptibility [50] and concluded that overall, research on brain wave activity using EEG support behavioural research which has found that HHs had superior focusing and attentional abilities as measured by the Tellegen Absorption Scale and the Differential Attentional Processes Inventory. Burrows et al. [48], also reviewed studies which looked at hemispheric asymmetries among HHs and stated that at neurophysiological level in both hypnotic and non-hypnotic conditions Highly Hypnotizable (HHs) individuals appear to have greater EEG hemispheric specificity.

The researchers speculated this may relate to the fact that HHs are more adept at sustaining attention, becoming deeply involved in something and also seem to possess a greater ability to switch from one task to another. Trippe, Weiss \& Miltner [51] in an EEG experiment tracking changes in brain activity during hypnosis found a breakdown in functional connectivity of the gamma band between somatosensory and frontal cortices. They hypothesised that the state of hypnosis signified a comprehensive breakdown in the organisation of oscillations by the areas in the frontal cortices when a person enters a state of hypnosis. These oscillations refer to activity of the neurons which can be measured by EEG because of the electrochemical impulses which register at different frequencies. Fingelkurts,
Fingelkurts \& Kahonen [52] described functional connectivity as the mechanism for the co-ordination of activty between different neuron assemblies with the purpose of accomplishing a complex cognitive task or perceptual process.

One HH subject, studied by Fingelkurts, Fingelkurts, Kallio \& Renonsuo [53] on two independent occasions which were a year apart found that hypnosis caused a reorganization in the composition of the brain oscillations which did not immediately return to baseline when the individual emerged from hypnosis. They summarised their results in four points. 1. Hypnosis altered the complete amount of time (percentage of EEG segments) that particular types of brain oscillations were observed, as opposed to their amplitude or power; 2. Hypnosis induced significant changes in the organization of the brain oscillations in EEG; 3. The types of SPs during hypnosis were the same as those found in baseline but in the Fp1 and FP2 electrodes, seven of the seventeen SP types were only present during hypnosis and 4. They observed that the dominant SPs did not alter during hypnosis. Rather, the altered patterns represented non-dominant spectral patterns in the EEG.

Additionally, these changes were specific with respect to their spectral composition and the brain area. They concluded from their case study that hypnosis may be accompanied by a changed pattern of neural activity in the brain. Their findings were not replicated by Jensen et al. [54] who studied the effects of hypnosis and three other non-pharmacological pain therapies on brain states in 31 participants. Their objective was to look at brain oscillations occurring in response to these treatments and evaluate the associations, if any, with changes in pain intensity. Their findings were that changes in pain intensity were not associated with changes in brain oscillations. They concluded that brain activity as measured by EEG was not a useful method of measuring or explaining the benefits associated with these treatments. The different findings in the studies by Jensen et al. [54] and Fingelkurts et al. [53] may possibly be explained by the fact that the participant in Fingelkurts study was highly hypnotizable and in the study by Jensen et al., [54] hypnotizability was not an inclusion factor for the thirty-one individuals who completed the study. The perception of pain is a complex process.

De Benedittis [55] described pain as a multidimensional experience which is essentially sensory-discriminative, motivational-affective and cognitive and which is registered on several levels and sites of the central nervous system. The demarcation of different brain networks involved in hypnotic analgesia is well supported in the literature. Neuroimaging techniques have been used to determine brain structures linked to sensory and affective dimensions of pain [56] and the changes in pain perception when in a state of hypnosis [57]. A thorough review of the literature by Patterson \& Jensen [58] found that highly hypnotizable subjects show different patterns of cortical responding than those who rate as low (LH) on suggestibility measures. They say however that based on a meta-analysis by 


\section{Current Trends in Clinical \& Medical Imaging}

Montgomery, DuHamel \& Redd [59] up to $75 \%$ of the population could gain significant benefit from using hypnotic analgesia and that hypnotic analgesia works equally well in the medical and in the laboratory setting.

\section{References}

1. Tan G, Craine MH, Blair MJ, Garcia MK, Giordano J, et al. (2007) Efficacy of selected complementary and alternative medicine interventions for chronic pain. Journal of Rehabilitation Research and Development 44(2): 195-222

2. Berman BM, Swyers JP (1999) Complementary medicine treatments for fibromyalgia syndrome. Bailliere's Clinical Rheumatology 13(3): 487-492.

3. Elkins G, Jensen MP, Patterson DR (2007) Hypnotherapy for the management of chronic pain. International Journal of Clinical and Experimental Hypnosis 55(3): 275-287.

4. Jensen MP, Patterson DR (2006) Hypnotic treatment of chronic pain. Journal of Behavioural Medicine 29(1): 95-124.

5. Stoelb BL, Molton IR, Jensen MP, Patterson DR (2009) The efficacy of hypnotic analgesia in adults: A review of the literature. Contemporary Hypnosis 26(1): 24-39.

6. Milling LS, Coursen EL, Shores J, Waszkiewicz JA (2010) The predictive validity of hypnotizability: The change in suggestibility produced by hypnosis. Journal of Consulting and Clinical Psychology 78(1): 126130

7. Flory N, Salazar GM, Lang EV (2007) Hypnosis for acute distress management during medical procedures. International Journal of Clinical and Experimental Hypnosis 55(3): 303-317.

8. Pearce (1977) Migraine: A psychosomatic disorder. Headache 17(3): 125-128.

9. Bushnell MC, Ceko M, Low LA (2013) Cognitive and emotional control of pain and it's disruption in chronic pain 14(7): 502-511.

10. MacDonnell J (2013) Mathematics department. Fairfield University, USA.

11. Ernst W (2004) Colonial psychiatry, magic and religion. The case of mesmerism in British India. History of Psychiatry 15(1): 057-071.

12. Bachner Melman R, Lichtenburg P (2001) Freud's relevance to Hypnosis. A Reevaluation. American Journal of Clinical Hypnosis 44(1): 37-50.

13. Feldman JB (1985) The work of Milton Erickson: A multisystem model of eclectic therapy. Psychotherapy: Theory, Research, Practice, Training 22(2): 154-162.

14. Piccione C, Hilgard ER, Zimbardo PG (1989) On the degree of stability of measured hypnotizability over a 25-year period. Journal of Personality and Social Psychology 56(2): 289-295.

15. Coon D, Mitterer JO (2008) Introduction to Psychology: Gateways to Mind and Behavior. (12 $2^{\text {th }}$ edn) Wadsworth Publishing Company, California, USA.

16. Woody EZ, Bowers KS (1994) A frontal assault on dissociated control. In: SJ Lynn, JW Rhue (Eds.), Dissociation: Clinical and theoretical perspectives Guilford Press New York, USA, p. 52-79.

17. Spiegel H (1977) The hypnotic induction profile (HIP): A review of its development. Annals of the New York Academy of Sciences 296: 129142

18. Jamieson GA, Woody E (2007) Dissociated control as a paradigm for cognitive neuroscience research and theorizing in hypnosis. In: GA Jamieson (Eds.), Hypnosis and conscious states: the cognitive neuroscience perspective. Oxford University Press, UK.
19. Lynn SJ, O Hagan S (2009) The Sociocognitive and Conditioning and Inhibition theories of hypnosis. Contemporary Hypnosis 26(2): 121-125.

20. Dienes Z, Brown E, Hutton S, Kirsch I, Mazzoni G, et al. (2009) Hypnotic suggestibility, cognitive inhibition, and dissociation. Consciousness and Cognition 18(4): 837-847.

21. Horton JE, Crawford HJ, Harrington G, Downes JH $3^{\text {rd }}$ (2004) Increased anterior corpus callosum size associated positively with hypnotizability and the ability to control pain. Brain 127: 1741-1747.

22. Milling LS, Coursen EL, Shores J, Waszkiewicz JA (2010) The predictive validity of hypnotizability: The change in suggestibility produced by hypnosis. Journal of Consulting and Clinical Psychology 78(1): 126130.

23. Milling LS (2008) Recent developments in the study of hypnotic pain reduction: A new golden era of research? Contemporary Hypnosis 25(304): 165-177.

24. Green JP, Barabasz AF, Barrett D, Montgomery GH (2005) Forging ahead, the 2003 APA Division 30 definition of hypnosis. International Journal of Clinical and Experimental Hypnosis 53(3): 259-264.

25. Spiegel H (1977) The hypnotic induction profile (HIP): A review of its development. Annals of the New York Academy of Sciences 296: 129142.

26. Spiegel H, Spiegel D (2004) Trance \& Treatment. Clinical Uses of Hypnosis. ( $\left.2^{\text {nd }} e d n\right)$, American Psychiatric Publishing Ltd. Washington DC, USA.

27. Grant CD, Nash MR (1995) The Computer-Assisted Hypnosis Scale: Standardization and Norming of a Computer-Administered Measure of Hypnotic Ability. Psychological Assessment 7(1): 49-58.

28. Spiegel H (1974) The grade 5 syndrome: The highly hypnotizable person. The International Journal of Clinical and Experimental Hypnosis 22(4): 303-319.

29. Friedman H, Taub HA, Sturr JF, Monty RA (1987) Visual information processing speed in hypnotized and nonhypnotized subjects. Journal of General Psychology 114(4): 363-372.

30. Angelini FJ, Kumar VK, Chandler L (1999) The Harvard Group Scale of Hypnotic Susceptibility and related instruments: individual and group administrations. International Journal of Clinical and Experimental Hypnosis 47(3): 236-250.

31. Weitzenhoffer AM, Hilgard ER (1962) Stanford Hypnotic Susceptibility Scale, Form C. Palo Alto, CA: Consulting Psychologists Press.

32. Morgan AH, Hilgard JR (1978) The Stanford Hypnotic Clinical Scale for Adults, American Journal of Clinical Hypnosis 21(2-3): 134-147.

33. Nadon R, Hoyt IP, Register PA, Kihlstrom JF (1991) Journal of Personality and Social Psychology. Absorption and hypnotisability. context effects reexamined 60(1): 144-153.

34. Grant CD, Nash MR (1995) The Computer-Assisted Hypnosis Scale: Standardization and Norming of a Computer-Administered Measure of Hypnotic Ability. Psychological Assessment 7(1): 49-58.

35. Spiegel H (1972) An eye-roll test for hypnotizability. The American Journal of Clinical Hypnosis 15(1): 25-28.

36. Orne MT, Hilgard ER, Spiegel H, Spiegel D, Crawford HJ, et al. (1979) The relation between the Hypnotic Induction Profile and the Stanford Hypnotic Susceptibility Scales, Forms A and C. International Journal of Clinical and Experimental Hypnosis 27(2): 85-102.

37. Stoelb BL, Molton IR, Jensen MP, Patterson DR (2009) The efficacy of hypnotic analgesia in adults: A review of the literature. Contemporary Hypnosis 26(1): 24-39.

38. Santarcangelo EL, Sebastiani L (2004) Hypnotizability as an adaptive trait. Experimental Report 21(1): 3-13. 
39. Lichtenberg P, Bachner Melman R, Gritsenko I, Ebstein RP (2000) Exploratory association study between catechol-0-methyltransferase (COMT) high/low enzyme activity polymorphism and hypnotizability. American Journal of Medical Genetics 96(6): 771-774.

40. Spiegel D, King R (1992) Hypnotizability and CSF HVA levels among psychiatric patients. Biological Psychiatry 31(1): 95-98.

41. Szekely A, Kovacs Nagy R, Bányai EI, Gősi Greguss AC, Varga K, et al. (2010) Association Between Hypnotizability and the Catechol-O-Methyltransferase (COMT) Polymorphism, International Journal of Clinical and Experimental Hypnosis 58(3): 301-315.

42. RAZ A (2005) Attention and Hypnosis: Neural Substrates and Genetic Associations of Two Converging Processes. International Journal of Clinical and Experimental Hypnosis 53(3): 237-258.

43. Benedetti F (2007) The Placebo and Nocebo Effect: How the therapists words act on the patient's brain. Karger Gazette. Mind \& Body 69: 7-9.

44. Benedetti F, Amanzio M (1997) The neurobiology of placebo analgesia: from endogenous opioids to cholecystokinin. Progress in Neurobiology 51: 109-125.

45. Spiegel D, Albert LH (1983) Naloxone fails to reverse hypnotic alleviation of chronic pain. Psychopharmacology 81(2): 140-143.

46. Nusbaum F, Redouté J, Le Bars D, Volckmann P, Simon F, et al. (2011) Chronic low-back pain modulation is enhanced by hypnotic analgesic suggestion by recruiting an emotional network: A PET imaging study. International Journal of Clinical and Experimental Hypnosis 59(1): 2744 .

47. Horton J, Crawford HJ, Harrington G, Downs HJ (2004) Increased anterior corpus callosum size associated positively with hypnotizability and the ability to control pain. Brain 127(8): 1741-1747.

48. Burrows GD, Stanley RO, Bloom PB (2001) International Handbook of Clinical Hypnosis. Chichester, Wiley.

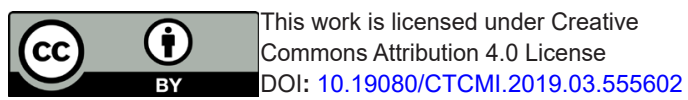

49. Schacter L (1977) EEG theta waves and psychological phenomena: A review and analysis. Journal of Biological Psychology 5(1): 47-82.

50. Crawford H J (1990) Cognitive and psychophysiological correlates of hypnotic responsiveness and hypnosis. In: ML Fass, D Brown (Eds.), Creative mastery in hypnosis and hypnoanalysis: A Festschrift for Erika Fromm Hillsdale, NJ, Lawrence Erlbaum Associates, US p. 4754.

51. Trippe RH, Weiss T, Miltner WHR (2004) Hypnotically induced analgesia - mechanisms. Anasthesiol Intensiv 45: 642-647.

52. Fingelkurts AA, Fingelkurts AA, Kahkonen S (2005) Functional connectivity in the brain. is it an elusive concept? Neuroscience and Biobehavioural Reviews 28(8): 827-836.

53. Fingelkurts A, Fingelkurts A, Kallio S, Revonsuo A (2007) Hypnosis induces a changed composition of brain oscillations in EEG: A case study. Contemporary Hypnosis 24(1): 3-18.

54. Jensen MP, Sherlin LH, Askew RL, Fregni F, Witkop AG, et al. (2013) Effects of non-pharmacological pain treatments on brain states. Clinical Neurophysiology 124: 2016-2024.

55. De Benedittis G (2003) Understanding the Multidimensional Mechanisms of Hypnotic Analgesia. Contemporary Hypnosis 20(2): 59-80.

56. Feldman (2004) The neurobiology of pain, affect and hypnosis. American Journal of Clinical Hypnotherapy 46(3): 187-200.

57. Vanhaudenhuyse A, Boly M, Laureys S, Faymonville M (2009) Neurophysiological correlates of hypnotic analgesia. Contemporary Hypnosis 26(1): 15-23.

58. Patterson DR, Jensen MP (2003) Hypnosis and Clinical Pain. Psychological Bulletin 129(4): 495-521.

59. Montgomery GH, Duhamel KN, Redd WH (2000) A meta-analysis of hypnotically induced analgesia: How effective is hypnosis? International Journal of Clinical and Experimental Hypnosis 48(2): 138-153.

\section{Your next submission with Juniper Publishers will reach you the below assets}

- Quality Editorial service

- Swift Peer Review

- Reprints availability

- E-prints Service

- Manuscript Podcast for convenient understanding

- Global attainment for your research

- Manuscript accessibility in different formats

\section{( Pdf, E-pub, Full Text, Audio)}

- Unceasing customer service

Track the below URL for one-step submission

https://juniperpublishers.com/online-submission.php 